\title{
Envelope Protein Synthesis and Inhibition of Cell Division in Escherichia coli during Inactivation of the B Subunit of DNA Gyrase
}

\author{
By ENRIQUE HERRERO, $\dagger$ NEIL F. FAIRWEATHER AND \\ I. BARRY HOLLAND* \\ Department of Genetics, University of Leicester, Leicester LE1 7RH, U.K.
}

(Received 21 April 1981)

\begin{abstract}
The rates of synthesis of inner and outer membrane proteins of Escherichia coli $\mathrm{K} 12$ during inhibition of cell division have been studied. When cell division was inhibited, either by treatment of wild-type cells with the antibiotic clorobiocin (an inhibitor of the B subunit of DNA gyrase) or by a temperature shift of a gyrB-ts mutant, a $40 \%$ reduction in the rate of synthesis of total outer membrane protein relative to that of the inner membrane was observed. When a gyrB-ts mutant was shifted to high temperature under conditions which allowed continued cell division, this large reduction in the rate of synthesis of outer membrane protein relative to inner membrane protein was not observed. In contrast to the results obtained with clorobiocin, inhibition of cell division by the $\beta$-lactam antibiotic cefuroxime did not cause any detectable disturbance in the rate of synthesis of either inner or outer membrane protein. This demonstrates that inhibition of septum formation per se does not perturb synthesis of envelope protein.

The data obtained are consistent with a model in which the rate of synthesis and therefore expansion of outer membrane is one of many conditions which must be satisfied before septum formation can occur. The results are discussed in relation to such a model, and to previous findings which have shown that the rate of synthesis of outer membrane proteins displays a linear mode with an abrupt doubling in rate at a discrete point in the cell cycle.
\end{abstract}

\section{INTRODUCTION}

The processes of septation and cell division in Escherichia coli are presumably tightly coupled to the synthesis of the cell envelope, although the mechanism of this coupling is unclear. Models for the control of cell division in $E$. coli have been greatly influenced by studies of the Gram-positive coccus Streptococcus faecalis, in which surface growth is restricted to an equatorial growth zone which eventually becomes the site for cross-wall formation (Higgins \& Shockman, 1970). Although some evidence for zonal growth in $E$. coli has been presented, the data are still controversial. Nevertheless, many models involve the triggering of an abrupt doubling in the number of such sites or growth zones as an essential prerequisite for division (Helmstetter et al., 1979). This in turn predicts that certain surface components should be synthesized at a constant rate with an abrupt doubling in the rate at some point in the cell cycle; such a linear pattern of synthesis has now been demonstrated for both peptidoglycan (Hoffman et al., 1972) and outer membrane protein (Churchward \& Holland, 1976; Boyd \& Holland, 1979) in E. coli. In contrast, cell mass increases exponentially, and Pritchard (1974) has argued that the relative excess of surface material being synthesized shortly after the doubling in rate might be sufficient to promote invagination of the surface layers and hence cross-wall formation.

\footnotetext{
† Present address: Departamento de Microbiologia, Facultad de Farmacia, Universidad de Valencia, Valencia, Spain.
} 
In $E$. coli, cell division may be blocked by many treatments which inhibit DNA replication, and models have been presented invoking the dependence of cell division upon the successful completion of an event in the DNA replication cycle, e.g. initiation or termination of replication. However, it is now clear that the recA-dependent, SOS repair system is induced upon such treatments to promote, amongst other effects, inhibition of cell division (Witkin, 1976; Darby \& Holland, 1979). The possible dependence of division upon a specific event in the DNA replication cycle is therefore still an open question.

DNA gyrase is an enzyme which introduces negative supercoils into plasmid DNA in vitro (Gellert et al., 1976a). In E. coli $\mathrm{K} 12$, this enzyme is composed of the A subunit, specified by the gyrA gene, and inhibited by nalidixic or oxolinic acid (Gellert et al., 1977; Sugino et al., 1977), and the B subunit, or gyrB product, which is inhibited by novobiocin and coumermycin (Gellert et al., 1976 b; Bachmann \& Low, 1980). Recently, we observed that clorobiocin, another inhibitor of the B subunit of DNA gyrase, effectively blocked cell division as well as inhibiting DNA synthesis, although the SOS pathway was not induced (Fairweather et al., 1980). We also found that cell division was perturbed upon shift of a temperature-sensitive gyrB mutant to the non-permissive temperature (Orr et al., 1979). We have now examined the synthesis of bulk envelope proteins in clorobiocin-treated cells and in a temperature-sensitive gyrB mutant in an attempt to determine the mechanism of this division block. The results obtained suggest that when the activity of the B subunit of gyrase is inhibited and cell division is blocked, there is an immediate reduction in the rate of synthesis of outer membrane protein relative to that of the inner membrane or total cell protein. The correlation between this reduction in rate of outer membrane protein synthesis and inhibition of cell division is discussed.

\section{METHODS}

Bacterial strains, media and growth conditions. Escherichia coli $\mathrm{K} 12$ strain LE234 metB ilv argH rpsL tha thi

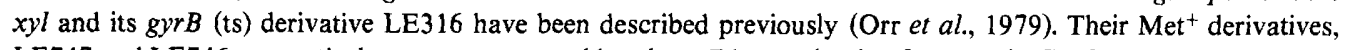
LE747 and LE746, respectively, were constructed by phage P1 transduction from strain C600.

Cultures were grown at the indicated temperatures in M9 minimal medium containing glucose $(0.4 \%, \mathrm{w} / \mathrm{v})$ and essential amino acids $\left(40 \mu \mathrm{g} \mathrm{m}^{-1}\right)$. Casamino acids $(0.1 \%, \mathrm{w} / \mathrm{v})$ were added where indicated.

Measurements. Apparent absorbance of bacterial cultures was measured at $450 \mathrm{~nm}$ using a Gilford spectrophotometer. Cell number was determined by counting samples in $0.9 \%(\mathrm{w} / \mathrm{v})$ saline using a model B Coulter counter. The rate of protein synthesis was determined by measuring incorporation of $\left[{ }^{35} \mathrm{~S}\right]$ methionine into trichloroacetic acid (TCA) precipitable material after a $5 \mathrm{~min}$ pulse of $1 \mathrm{ml}$ of culture with $10 \mu \mathrm{Ci}\left[{ }^{35} \mathrm{~S}\right]$ methionine.

Cell envelopes. Cell envelopes were isolated and fractionated into inner and outer membranes by virtue of their differential solubility in Sarkosyl NL97 as described previously (Boyd \& Holland, 1979). To obviate the need for reproducible recovery between samples of membrane fractions, identical amounts of carrier cells labelled for two generations with $\left[{ }^{3} \mathrm{H}\right]$ leucine were added to each sample before processing as described by Boyd \& Holland (1979). The rates of synthesis of membrane fractions are therefore expressed as ${ }^{35} \mathrm{~S} /{ }^{3} \mathrm{H}$ ratios.

Chemicals. $\left[{ }^{35} \mathrm{~S}\right]$ Methionine $\left(50 \mu \mathrm{Ci} \mu \mathrm{g}^{-1}, 1.85 \mathrm{MBq} \mu \mathrm{g}^{-1}\right)$ and $\left[{ }^{3} \mathrm{H} \mid\right.$ leucine $\left(10 \mu \mathrm{Ci} \mu \mathrm{g}^{-1}, 370 \mathrm{kBq} \mu \mathrm{g}^{-1}\right)$ were from Amersham. Clorobiocin was a gift from May \& Baker Ltd, Dagenham, Essex. Cefuroxime was a gift from Dr B. G. Spratt.

\section{RESULTS}

\section{Effect of clorobiocin on envelope protein synthesis}

An exponentially growing culture of $E$. coli K12 LE747 was treated with clorobiocin (50 $\mu \mathrm{g} \mathrm{ml}^{-1}$ ) in $\mathrm{M} 9 /$ glucose medium; the culture was pulse-labelled with $\left[{ }^{35} \mathrm{~S}\right]$ methionine and the radioactive content of isolated inner and outer membranes was determined. The data obtained are shown in Fig. 1. After a slight initial drop, the rate of total protein synthesis remained constant for almost $1 \mathrm{~h}$. At the same time the rate of cell division was immediately reduced to about $16 \%$ of that in the untreated control. The rate of inner membrane protein synthesis showed a slight increase after addition of the drug whilst, in contrast, that of outer membrane 


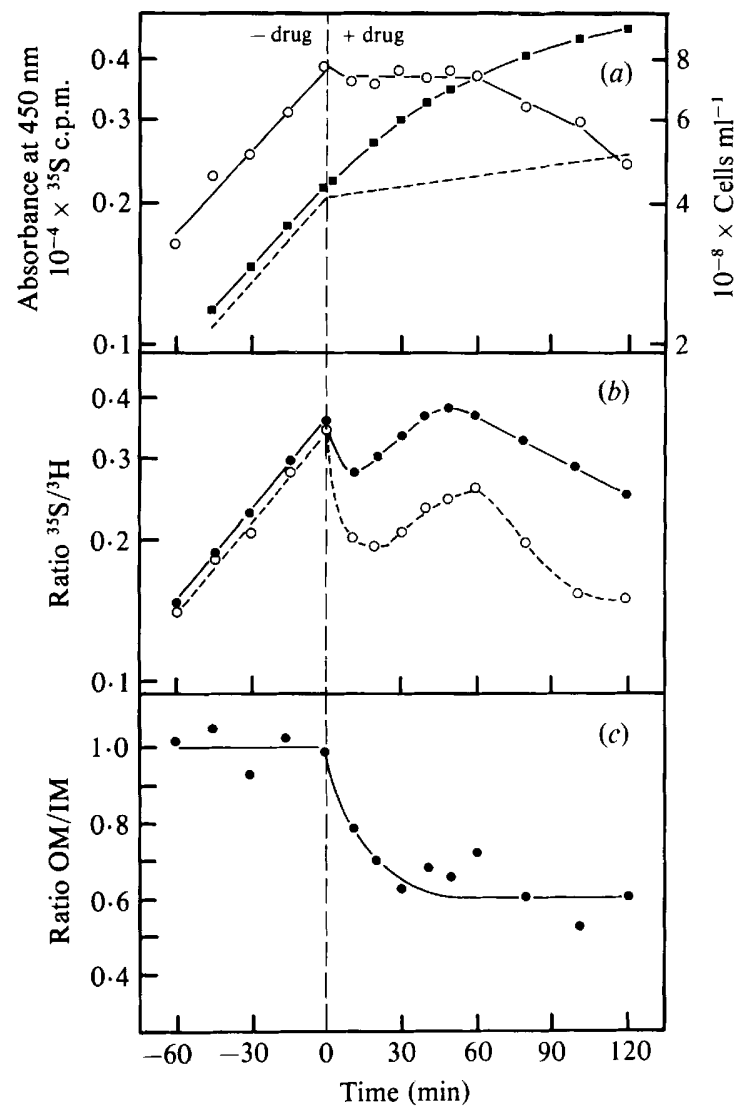

Fig. 1. Rates of synthesis of total protein and inner and outer membrane proteins in strain LE747 (wild-type) growing in glucose minimal medium at $37^{\circ} \mathrm{C}$ in the presence of clorobiocin $\left(50 \mu \mathrm{gl}^{-1}\right)$. The drug was added at time 0 . (a) Absorbance at $450 \mathrm{~nm}(\boldsymbol{D})$; TCA-precipitable ${ }^{35} \mathrm{~S}$ c.p.m. in total protein after a $5 \mathrm{~min}$ pulse with $\left[{ }^{35} \mathrm{~S} /\right.$ methionine $(\mathrm{O})$; cell number, determined in a similar culture (see Fairweather et al., 1980) (---). (b) Ratio $\left[{ }^{35} \mathrm{~S}\right]$ methionine to $\left[{ }^{3} \mathrm{H} \mid\right.$ leucine (present in protein of uniformly labelled carrier cells) in the bulk inner $(O)$ and outer $(O)$ membrane proteins. (c) Ratio of bulk outer membrane to inner membrane proteins (OM/IM): values are normalized considering the ratio $\mathrm{OM} / \mathrm{IM}$ in the absence of clorobiocin as $1 \cdot 0$.

protein fell. The net effect was that the rate of synthesis of outer membrane protein relative to that of the inner membrane fell by $40 \%$ during the first 30 min before reaching a new constant level (Fig. 1c). Therefore, coincident with inhibition of cell division, treatment with clorobiocin produced a marked fall in the rate of synthesis and/or assembly of bulk outer membrane protein relative to that of the inner membrane. Major changes in the pattern of synthesis of a number of individual outer membrane proteins (the products of the omp $A, F$ and $C$ genes) were also observed but these could not be correlated with the division inhibition (data not shown). However, the analysis of these proteins in whole envelopes as well as in the outer membrane fraction remaining after Sarkosyl extraction confirmed the overall reduction in the rate of outer membrane protein synthesis indicated above. Similarly, examination of gel profiles of separated membrane fractions failed to reveal any contamination of the inner membrane with outer membrane proteins after treatment of the bacteria with the drug. These results indicated that the apparent reduction in the level of incorporation of $\left[{ }^{35} S\right]$ methionine into the outer membrane was a true reflection of a reduced rate of synthesis and not due to retarded assembly or to an abnormal sensitivity of outer membrane proteins synthesized in the presence of the drug to extraction by Sarkosyl. 


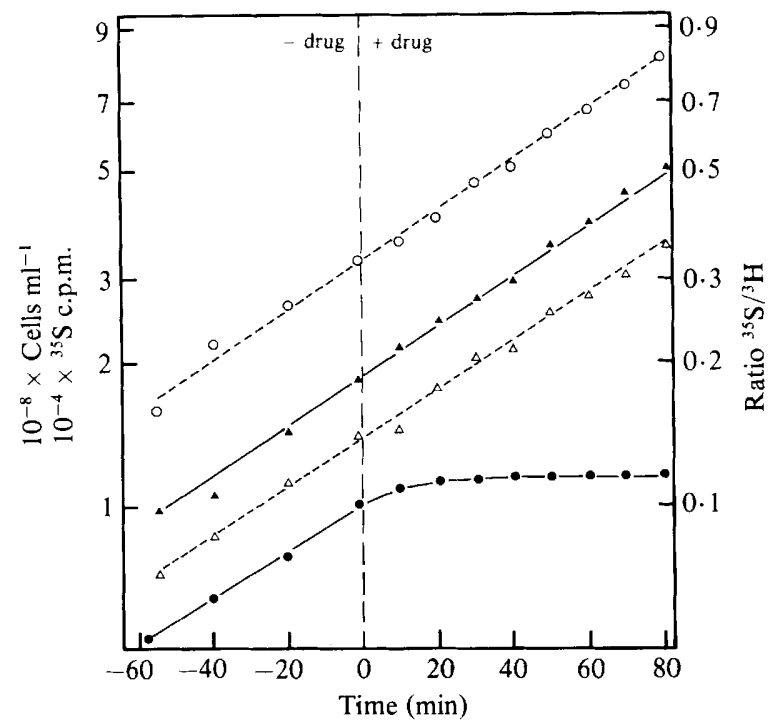

Fig. 2. Rates of synthesis of total protein and inner and outer membrane proteins in strain LE747 (wild-type) growing in glucose minimal medium at $32{ }^{\circ} \mathrm{C}$ in the presence of cefuroxime $\left(6 \mu \mathrm{g} \mathrm{ml}^{-1}\right)$. The drug was added at time 0 . Cell number (O); TCA-precipitable ${ }^{35} \mathrm{~S}$ c.p.m. in total protein after a $5 \mathrm{~min}$ pulse $(\mathrm{O})$; ratio of ${ }^{35} \mathrm{~S}$ to ${ }^{3} \mathrm{H}$ in bulk inner membrane $(\Delta)$ and outer membrane $(\triangle)$ proteins.

\section{Envelope protein synthesis after inhibition of division by cefuroxime}

Cefuroxime is a specific inhibitor of penicillin binding protein 3 and therefore causes filamentation of bacteria by interfering with peptidoglycan synthesis (Spratt, 1979). Treatment with this drug $\left(6 \mu \mathrm{g} \mathrm{m}^{-1}\right)$ immediately blocked cell division in strain LE747 without any detectable effect upon mass increase for at least $80 \mathrm{~min}$ (Fig. 2). Division inhibition in this case was not accompanied by any significant change in the rate of synthesis of either bulk envelope proteins (Fig. 2) or any of the individual outer membrane proteins analysed. Inhibition of septum formation per se therefore does not lead to gross disturbance of outer membrane protein synthesis.

\section{Envelope protein synthesis in a temperature-sensitive gyrB mutant}

We have previously described a clorobiocin-resistant mutant (strain LE316 and its Met $^{+}$ derivative LE746) carrying a conditional lethal mutation in gyrB. After shifting this mutant to high temperature, nuclear organization was disrupted and RNA synthesis and initiation of chromosomal replication, but not on-going DNA replication, were inhibited (Orr et al., 1979). More recent studies have shown that extracts of this strain lack any detectable activity of the B subunit of DNA gyrase and that supercoiled forms of ColE1 plasmid are rapidly lost when the mutant is shifted to high temperature (Orr \& Staudenbauer, 1980). We conclude that the changes in the mutant at the non-permissive temperature can be ascribed to loss of gyrase activity and to a consequent reduction in the degree of supercoiling of the chromosome.

In our earlier study we observed that in M9 medium supplemented with Casamino acids, cell division in the mutant continued at the non-permissive temperature after a short lag, producing many DNA-less cells. However, division was greatly reduced at $43{ }^{\circ} \mathrm{C}$ when the mutant was grown in unsupplemented M9 medium (Fig. $3 a$ ). Nevertheless, under these conditions the pattern of DNA synthesis (data not shown) was essentially identical to that in the rich medium described previously (Orr et al., 1979). The analysis of envelope synthesis in the mutant in the two media is shown in Figs 3 and 4 . Inhibition of division in the 


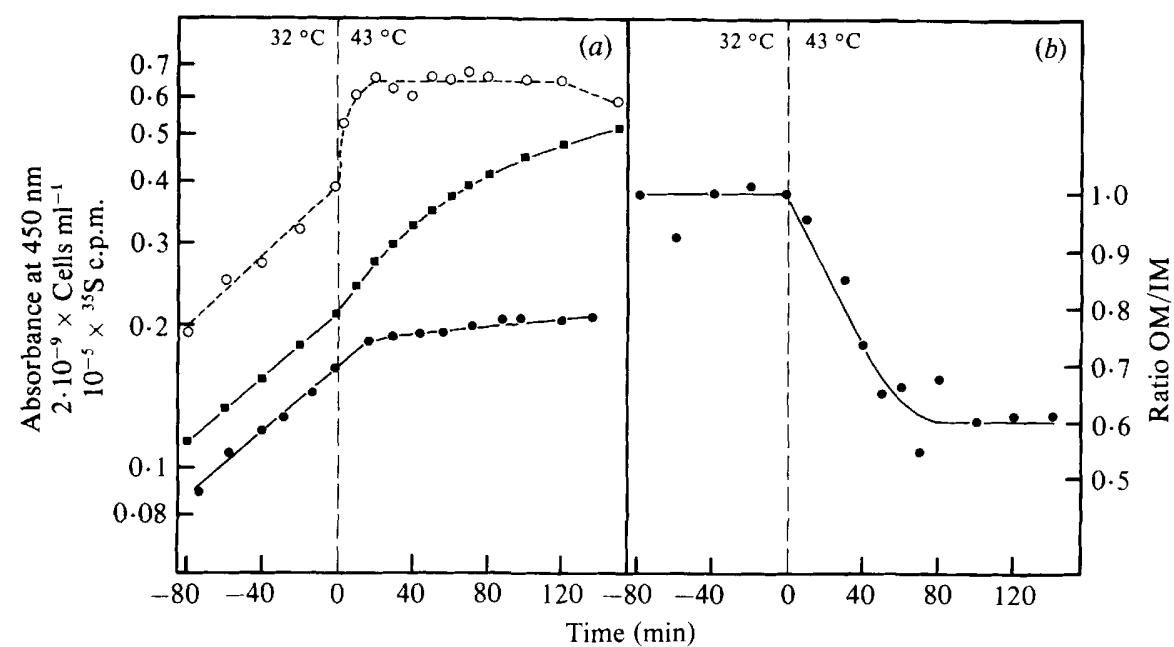

Fig. 3. Rates of synthesis of total protein and inner and outer membrane proteins in strain LE746 ( $g v r B$ ) growing in glucose minimal medium. At time 0 the culture was transferred from $32^{\circ} \mathrm{C}$ to $43{ }^{\circ} \mathrm{C}$. (a) Absorbance at $450 \mathrm{~nm}(\boldsymbol{\square})$; cell number $(\mathrm{O})$ : TCA-precipitable ${ }^{35} \mathrm{~S}$ c.p.m. in total protein after a 5 min pulse (O). (b) Normalized ratio of bulk outer membrane to inner membrane proteins $(\mathrm{OM} / \mathrm{IM})$.

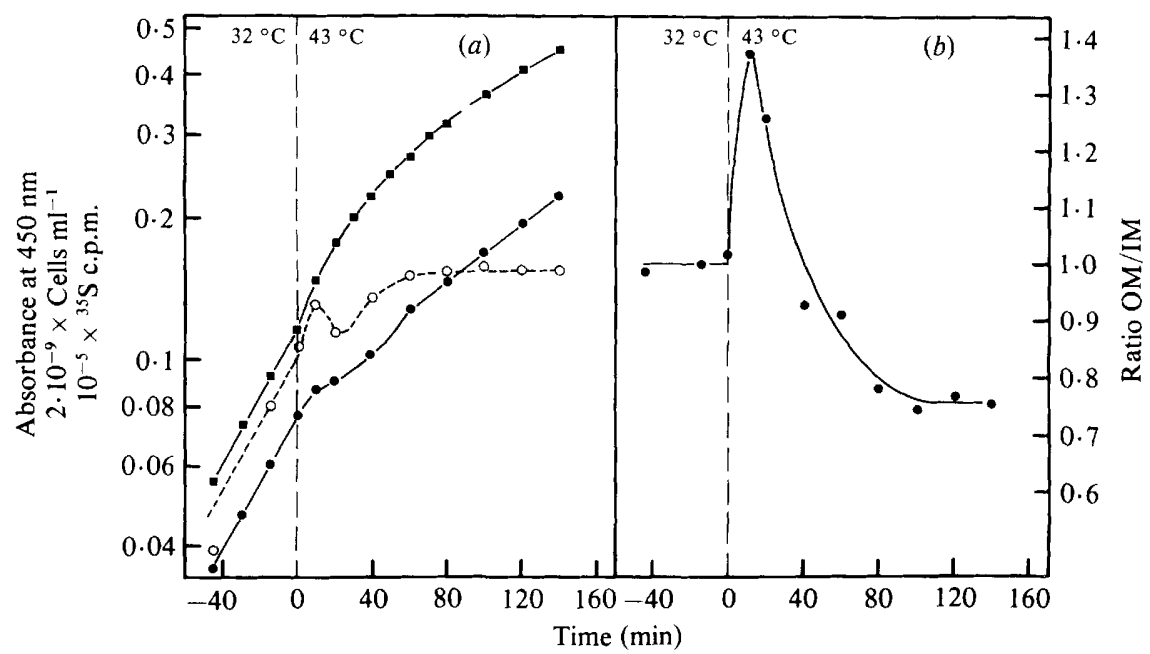

Fig. 4. Rates of synthesis of total protein and inner and outer membrane proteins in strain LE746 $($ gyr $B)$ growing in glucose minimal medium plus $0.1 \%$ Casamino acids. At time 0 the culture was transferred from $32{ }^{\circ} \mathrm{C}$ to $43^{\circ} \mathrm{C}$. (a) Absorbance at $450 \mathrm{~nm}$ (四); cell number (O); TCA-precipitable ${ }^{35} \mathrm{~S}$ c.p.m. in total protein after a $5 \mathrm{~min}$ pulse $(\mathrm{O})$. (b) Normalized ratio of bulk outer membrane to inner membrane proteins (OM/IM).

unsupplemented medium at $43^{\circ} \mathrm{C}$ was immediately accompanied by a $40 \%$ reduction in the rate of outer membrane protein synthesis relative to that of the inner membrane (Fig. $3 b$ ). In fact, the differential rate of inner membrane protein synthesis (compared to total protein) was unchanged after the temperature shift whilst that of the outer membrane fell (data not shown). Moreover, as in the case of clorobiocin treatment, we could find no evidence that the observed fall in the ratio of outer to inner membrane proteins was due to an alteration in the efficiency of separation of the membranes by Sarkosyl. 


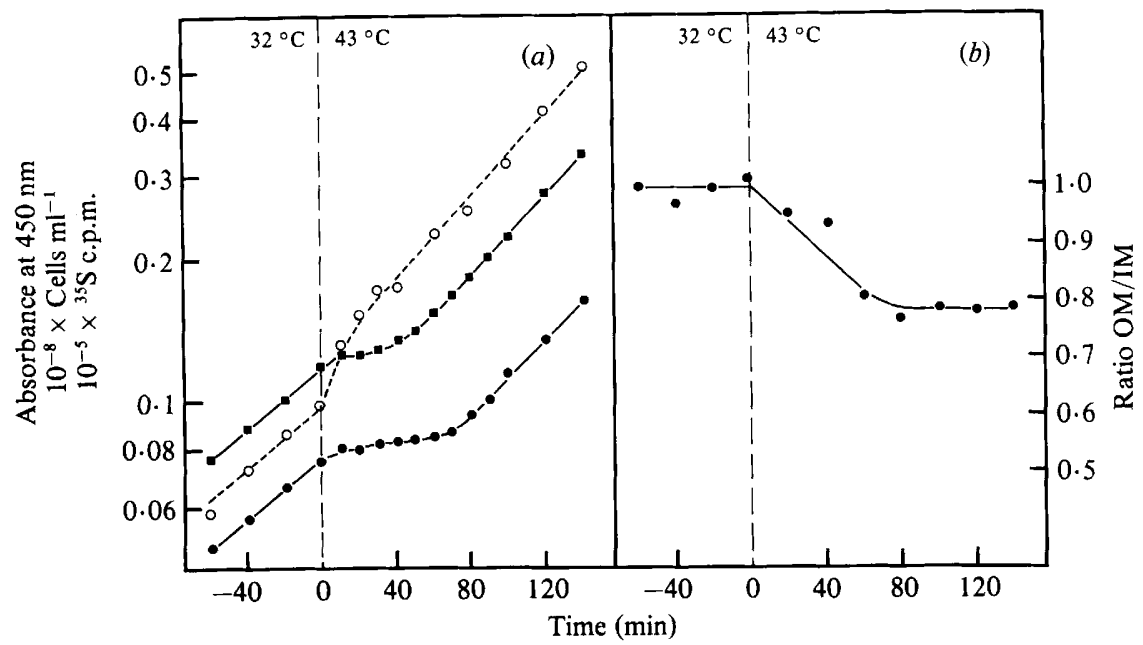

Fig. 5. Rates of synthesis of total protein and inner and outer membrane proteins in strain LE747 (wild-type) growing in glucose minimal medium. At time 0 the culture was transferred from $32^{\circ} \mathrm{C}$ to $43^{\circ} \mathrm{C}$. (a) Absorbance at $450 \mathrm{~nm}(\mathbf{G})$; cell number (O); TCA-precipitable ${ }^{35} \mathrm{~S}$ c.p.m. in total protein after a 5 min pulse $(O)$. (b) Normalized ratio of bulk outer membrane to inner membrane proteins (OM/IM).

Maintenance of division capacity by growth in the richer medium was associated with a relative stimulation of outer membrane protein synthesis upon temperature shift, although the rate relative to that of inner membrane protein synthesis eventually fell to about $80 \%$ of the pre-shift rate (Fig. $4 b$ ). At these later times, as shown previously (Orr et al., 1979), division is still perturbed with the production of many small, DNA-less cells.

Analysis of the rate of synthesis of individual outer membrane proteins in the gyrB-ts mutant after a temperature shift again revealed a gross disturbance in the pattern of synthesis (data not shown). However, these effects were observed in the mutant independently of the growth medium and therefore independently of the extent of division inhibition. In fact, very similar changes were also observed upon temperature shift of the wild-type strain (see Discussion).

\section{Envelope protein synthesis and division in wild-type strains shifted to high temperature}

As a control for the effect of temperature in the experiment with the gyrB mutant, we also analysed envelope protein synthesis in wild-type strains shown in $\mathrm{M} 9 /$ glucose medium after a temperature shift. Division was partially inhibited at $43{ }^{\circ} \mathrm{C}$ for about $70 \mathrm{~min}$ in the wild-type parental strain LE747 (Fig. 5a). There was also a slight delay in the increase in absorbance after the shift although the rate of protein synthesis increased immediately. Since RNA constitutes a large proportion of cell mass, this suggests that the relative rate of RNA synthesis was transiently reduced at high temperature. As a result of all these transitional changes the mass per cell had increased significantly when the steady state rate of division was re-established. A similar delay in division after the shift was obtained with another wild-type strain, $E$. coli $\mathrm{K} 12 \mathrm{C} 600$ (data not shown), and may be a characteristic feature of E. coli $\mathrm{K} 12$ strains at high temperatures.

The early inhibition of division in strain LE747 was again accompanied by a fall in the rate of outer membrane protein synthesis relative to that of the inner membrane (Fig. $5 b$ ). In this case, however, the rate then levelled out at $80 \%$ of the pre-shift value. This suggests that under the new steady state conditions established at the high temperature, a reduced rate of outer membrane protein synthesis was sufficient to maintain division. 
Previous studies have shown that in $E$. coli both the peptidoglycan layer (Hoffman et al., 1972; Koppes et al., 1978) and the proteins in the outer membrane (Churchward \& Holland, 1976) are laid down linearly during the cell cycle; the rate of synthesis of these components is constant in the early part of the cell cycle but doubles abruptly a short time before division. In contrast, the rate of synthesis of the great majority of cellular proteins, including those in the inner membrane which constitute approximately $50 \%$ of all envelope protein, increases exponentially throughout the cell cycle. In consequence, the rate of synthesis or expansion of the outermost layers of the $E$. coli cell envelope should, late in the cycle, exceed the rate of synthesis of both mass and inner membrane. In considering possible models for the regulation of cell growth, Previc (1970) and Pritchard (1974) have proposed that an abrupt increase in the relative rate of synthesis of major surface components might be sufficient to initiate surface invagination and hence trigger septum formation and division.

In our previous studies (Boyd \& Holland, 1979) we considered possible mechanisms which might control linear synthesis of the outer membrane protein. Although data were obtained which clearly indicated that outer membrane proteins competed for sites of synthesis and assembly into the envelope, we concluded that the availability of such sites could not be the limiting factor since this would require the complicated hypothesis that the sites themselves are also synthesized linearly. Instead, we proposed that the overall rate of synthesis of outer membrane protein was constrained in the cycle by the rate of synthesis or expansion of an underlying structural template, the peptidoglycan layer. When the rate of synthesis of this layer doubles later in the cycle, responding perhaps to fluctuations in the availability of transcriptional and translational factors affecting enzymes directly concerned with peptidoglycan synthesis, the rate of outer membrane protein synthesis might also double.

In attempts to substantiate the hypothesis that the overall rate of synthesis of outer membrane proteins (and/or the peptidoglycan) is a critical factor in the timing of division, we have looked for conditions in which the rate of synthesis of this class of cellular proteins is differentially inhibited and have sought to correlate this with perturbation of cell division in $E$. coli. In this study, we have shown that inhibition of the B subunit of the enzyme DNA gyrase, through a temperature-sensitive mutation or by the use of the inhibitor clorobiocin, results in an immediate block to cell division and a $40-50 \%$ reduction in the relative rate of outer membrane protein synthesis. Inhibition of division at the non-permissive temperature in the gyrB mutant used here is, in fact, conditional. In rich medium, where division continues with the accumulation of many small, DNA-less cells (Orr et al., 1979), the rate of outer membrane protein synthesis (relative to that of the inner membrane) was initially stimulated although it did eventually fall by $15-20 \%$. This small fall in the relative rate was also observed in the wild-type strain shifted to $43{ }^{\circ} \mathrm{C}$ (Fig. $5 \mathrm{~b}$ ), and the reason for this is not understood. Careful inspection of the data, however, indicates that the wild-type strain, after a brief transitional stage, appeared to resume steady state growth at $43{ }^{\circ} \mathrm{C}$ with a new value for mass per cell which in turn may reflect a shape change and a new lower surface-to-mass ratio. Our results, therefore, are consistent with the hypothesis that an insufficiently high rate of synthesis of at least some surface components is sufficient to inhibit division in E. coli. Moreover, we have recently observed a dramatic reduction in the relative rate of outer membrane protein synthesis, coincident with inhibition of cell division, in a mutant of $E$. coli in which protein export sites in the inner membrane are apparently blocked by a hybrid protein coded by malE-lacZ gene fusion (Herrero, Bassford \& Holland, unpublished data).

In contrast, as shown by use of the antibiotic cefuroxime, inhibition of division in $E$. coli can occur without detectable effect on envelope protein synthesis (including that of the major outer membrane proteins). This striking result suggests that specific proteins like penicillin binding protein 3 , the cefuroxime target, must also play a vital role in division, for example in construction of the actual septum, quite independently of the overall rate of growth of the surface layers. 
In an attempt to correlate the inhibition of cell division with alterations in the rate of synthesis of specific polypeptides, we have measured accurately the rates of synthesis of the OmpF, C and A outer membrane proteins (data not shown). Marked changes in such rates were observed during clorobiocin treatment of wild-type cells and during a temperature shift of both the wild-type strain and the $\operatorname{gr} B$ mutant. However, no specific correlation could be demonstrated between these changes and the altered division pattern; these results will be discussed elsewhere.

The precise mechanism by which the inhibition of DNA gyrase results in division inhibition and a reduction in outer membrane protein synthesis is not clear. It is nevertheless probable that this involves loss of DNA supercoiling in the affected bacteria, leading to a reduced rate of transcription of some critical factor involved in peptidoglycan synthesis and/or the biogenesis of outer membrane proteins. Several previous studies have shown that transcriptional patterns are markedly altered both in vivo (Smith et al., 1978; Sanzey, 1979; Fairweather et al., 1980) and in vitro (Yang et al., 1979) when DNA gyrase is inhibited or supercoiling is drastically reduced.

This work was supported by an EMBO long-term Fellowship (to E.H.) and by an SRC-CASE studentship award (to N.F.F.) carried out in collaboration with May \& Baker Ltd. We are grateful to Elisha Orr and Walter Staudenbauer for communicating results prior to publication.

\section{REFERENCES}

BACHMANN, B. J. \& Low, K. B. (1980). Linkage map of Escherichia coli K-12. Edition 6. Microbiological Reviews 44, 1-56.

Boyd, A. \& Holland, I. B. (1979). Regulation of the synthesis of surface protein in the cell cycle of $E$. coli B/r. Cell 18, 287-296.

Churchward, G. G. \& Holland, I. B. (1976). Envelope synthesis during the cell cycle in Escherichia coli $\mathrm{B} / \mathrm{r}$. Journal of Molecular Biology 105, 245-261.

DARBY, V. \& Holland, I. B. (1979). A kinetic analysis of cell division and induction and stability of $r e c A$ protein in UV irradiated $l o n^{+}$and $l o n^{-}$strains of Escherichia coli K-12. Molecular and General Genetics 176, 121-128.

Fairweather, N. F., ORR, E. \& Holland, I. B. (1980). Inhibition of deoxyribonucleic acid gyrase: effects on nucleic acid synthesis and cell division in Escherichia coli K-12. Journal of Bacteriology 142, 153-161.

Gellert, M., Muzuuchi, K., O’Dea, M. H. \& Nash, H. A. (1976a). DNA gyrase: an enzyme that introduces superhelical turns into DNA. Proceedings of the National Academy of Sciences of the United States of America 73, 3872-3876.

Gellert, M., O'Dea, M. H., Iтoh, T. \& Tomizawa, J.-I. $(1976 b)$. Novobiocin and coumermycin inhibit DNA supercoiling catalysed by DNA gyrase. Proceedings of the National Academy of Sciences of the United States of A merica 73, 4474-4478.

Gellert, M., Mizuuchi, K., O'DeA, M. H., Itoh, T. \& TOMIZAWA, J.-I. (1977). Nalidixic acid resistance: a second genetic character involved in DNA gyrase activity. Proceedings of the National Academy of Sciences of the United States of America 74, 4772-4776.

Helmstetter, C. E., Pierucci, O., Weinberger, M., Holmes, M. \& TANG, M. (1979). Control of cell division in Escherichia coli. In The Bacteria, vol.
VII, pp. 517-579. Edited by I. C. Gunsalus \& R. Y. Stanier. New York: Academic Press.

Higgins, M. L. \& Shockman, G. D. (1970). Model for cell wall growth of Streptococcus faecalis. Journal of Bacteriology 101, 643-648.

Hoffman, B., Messer, W. \& Schwarz, U. (1972). Regulation of polar cap formation in the life cycle of Escherichia coli. Journal of Supramolecular Structure 1, 29-37.

Koppes, L. J. H., OverbeEke, N. \& NANninga, N. (1978). DNA replication pattern and cell wall growth in Escherichia coli PAT84. Journal of Bacteriology 133, 1053-1061.

OrR, E. \& Staudenbauer, W. (1980). An Escherichia coli mutant thermosensitive in the B subunit of DNA gyrase: effect on the structure and replication of the colicin E1 plasmid in vitro. Molecular and General Genetics 181, 52-56.

OrR, E., Fairweather, N. F., Holland, I. B. \& Pritchard, R. H. (1979). Isolation and characterisation of a strain carrying a conditional lethal mutation in the cou gene of Escherichia coli $\mathrm{K}-12$. Molecular and General Genetics 177, 103112.

Previc, E. P. (1970). Biochemical determination of bacterial morphology and the geometry of cell division. Journal of Theoretical Biology 27, 471497.

PrITCHARD, R. H. (1974). On the growth and form of the bacterial cell. Philosophical Transactions of the Royal Society B267, 303-336.

SANZEY, B. (1979). Modulation of gene expression by drugs affecting deoxyribonucleic acid gyrase. Journal of Bacteriology 138, 40-47.

Smith, C. L., Kubo, M. \& Iмамото, F. (1978). Promoter-specific inhibition of transcription by antibiotics which act on DNA gyrase. Nature, London 275, 420-423.

SpratT, B. G. (1979). Identification of the killing 
targets for $\beta$-lactam antibiotics. In Microbial Drug Resistance, vol. 2, pp. 349-360. Edited by S. Mitsuhashi. Tokyo: University of Tokyo Press.

Sugino, A., Peebles, C. L., Kreuzer, K. N. \& Cozzarelli, N. R. (1977). Mechanism of action of nalidixic acid: purification of Escherichia coli nalA gene product and its relationship to DNA gyrase and a novel nicking-closing enzyme. Proceedings of the National Academy of Sciences of the United States of America 74, 4767-4771.
WITKIN, E. M. (1976). Ultraviolet mutagenesis and inducible DNA repair in Escherichia coli. Bacteriological Reviews 40, 869-907.

YanG, H. L., Heller, K., Gellert, M. \& Zubay, G. (1979). Differential sensitivity of gene expression in vitro to inhibitors of DNA gyrase. Proceedings of the National Academy of Sciences of the United States of America 76, 3304-3308. 